Original Article

\title{
Incidence and Reasons for a Surgical Cancellation at a Hospital in Rwanda
}

\author{
Thierry Uwera ${ }^{1}$, Joselyne Mukantwari ${ }^{* 4}$, David Ryamukuru², Lilian A. Omondi ${ }^{2,3}$ \\ ${ }^{1}$ Operating theatre, Rwanda Military Hospital \\ ${ }^{2}$ School of Nursing and Midwifery, College of Medicine and Health Sciences, University of Rwanda \\ ${ }^{3}$ Rory Meyers College of Nursing, New York University \\ ${ }^{4}$ Faculty of Health Sciences, Arthur Labatt Family School of Nursing, University of Western Ontario, Canada
}

*Corresponding author: Joselyne Mukantwari. University of Rwanda, P.O. Box: 3286 Kigali, Rwanda. Email:mujoselyne@ gmail.com, Tel: +250788853576

\begin{abstract}
\section{Background}

Surgery cancellation is a challenging and costly event resulting in operating theatre inefficiency and psychological and financial problems for the patients and their families. This study aimed to find out the incidence and reasons for surgical cancellation at a Rwandan hospital.

\section{Methods}

A retrospective study was conducted on 736 patients' files obtained from theatre registry lists of surgical operations done from January to March 2017. The American Association of Perioperative Nurses (AORN) checklist for documenting cancelled surgical cases was used to establish the rate and reasons for cancellation. Data were analyzed using frequency and percentage descriptive statistics.
\end{abstract}

\section{Results}

Out of the 736 surgeries booked, 179 (24.3\%) were cancelled as follows: Orthopedic and general surgeries $(28.2 \%)$ respectively, gynecology and obstetrics $(27.4 \%)$, urology surgeries (15.5\%), maxillofacial surgeries (15.9\%), ENT (15.6\%) and plastic surgeries $(13.3 \%)$. Time constrain/long list $(19.6 \%)$, acute change in medical status $(10.6 \%)$, non-turn-up of the patient $(8.4 \%)$, and abnormal lab findings $(7.8 \%)$ were the most prevalent reasons.

\section{Conclusion}

The surgical cancellation rate at the study hospital was $24 \%$, increasing with the number of patients booked and the type of surgical procedure. A prospective study is required to gain more insight into the reason for cancellations, mostly amenable to mitigation measures. Rwanda J Med Health Sci 2021;4(3):379-386

Keywords: Surgical cancellation, Rwanda, surgical operation, operating theatre

\section{Background}

Globally, surgical cancellation rate varies from $1.6 \%$ to $40 \%$.[1-4] The rate is low in high income countries such as Saudi Arabia,[5] the United States of America (USA),[6] Finland,[7] Australia [4] while it is high in developing countries to include India, Pakistan[7] and African countries.[1] Causes of surgery cancellations have been found to be multifactorial and varying among countries.[1] In Saudi Arabia, the main causes were organizational issues, surgery-related issues, patient's medical status and staff availabilities.[5] In Nigeria, the cancellation rate was due to patients' issues (57.3\%), Hospital issues (40.3\%) and staff availability (2.4\%).[8]
In china, causes were medical conditions of patients $(59 \%)$, incomplete evaluation of patients $(17.7 \%)$ surgical and family reasons $(8.6 \%, 8.2 \%)$.[9] In the USA, the cancellation was related to overbooking (31\%) [4] and lack of theatre time (37.75\%).[10] In South Africa, $65.1 \%$ of cancelled surgeries were due to lack of medical clearance and non-preparation of the patients, and $25.8 \%$ of cancelled procedures were from surgeons' issues.[8]

Surgery cancellation is a challenging and expensive event due to significant drainage of hospital and patients resources.[11] It is the leading cause of inefficient theatre use, loss of hospital resources and time.[12] Cancellation causes emotional trauma to health care providers, patients and their families.[1] 
There is also financial implications to the patients and their families[8] in terms of working days lost and non-accomplishment of daily living activities.[4] High surgery cancellation rate has been associated with poor utilization of human resources, other hospital resources, increased patient charges due to prolonged hospitalization, prolonged and repeated preoperative care, leading to decreased staff and patients satisfaction and hospital-patient relationships.[1]

Some alternatives have been found to be effective in resolving the problem of high surgery cancellation rate. In Saudi Arabia, improved workflow, improved staffing, and human resource management helped decrease the surgery cancellation rate.[5] Introduction of preoperative preparation clinics in the United Kingdom reduced $50 \%$ of surgical cases cancelled and two-thirds of cases that used to be absent on the day of surgery.[5]

Although the hospitals are investing in building theatre infrastructures, developing human resources to ensure effective and efficient function of operating theatre (OR),[12] surgical cancellation is still frustrating for the surgical patients and OR staff. Appropriate preoperative assessment and care were revealed to be effective in reducing in half the surgical cancellation rate in the UK.[5] In Rwanda, no study was found that communicates incidence and reasons for surgical cancellations in the OR. This motivated the researchers to assess the reasons for surgery cases' cancellation on the day of surgery at a selected hospital theatre.

\section{Methods}

\section{Design, population and setting}

A retrospective cross-section study design was used for this study to portray the profile of surgical case cancellation rates at Rwanda Military Hospital (RMH) OR and associated reasons. $\mathrm{RMH}$ is a military referral hospital that treats $80 \%$ of civilian and $20 \%$ of military patients' references. It is located in the southeastern area of Kigali, on Kigali International Airport and Kanombe Military Camp road, Kanombe Sector and Kicukiro District. The hospital provides facilities for education in nursing and other allied health professions. Rwanda Military Hospital's main theatre comprises of 5 operating suites, it receives clients from all the wards within the hospital and accident and emergency departments. The theatres work on elective surgeries from Monday to Friday and 24 hours coverage of emergency surgeries.
As a referral hospital, it handles various specialized surgeries that cannot be done in district hospitals, including those related to ophthalmology, gynecology, obstetrics, pediatrics, urology, plastic and maxillofacial operations, among others. Rwanda Military Hospital has a bed capacity of 3000 . This study hospital admitted all patients referred from eastern district hospitals and was selected because it was the clinical site of the researchers and easily accessible.

\section{Sample size and sampling procedure}

The study population comprised theatre schedule lists and files of patients on the RMH OR list for surgery. The RMH admits about 250 clients per month, and the study was conducted for a period of three months, from January to March 2017. The target population was 750 clients, but the accessed population was 736 . No sampling strategy was used. All elective cases planned for surgeries were recorded for the study to help analyze the type of surgical procedure performed and the number of cancellations that occurred, and associated reasons. Any patients that were admitted to the theatre as emergency cases were excluded from the study.

\section{Data collection procedure}

A standard checklist developed by AORN, with possible reasons for surgical procedure cancellation, was used in this study. The checklist objective was to assist perioperative personnel with creating surgical cancellation reasons' documents in a health care system. It was adapted from published and validated AORN perioperative guidelines and clinical toolkits to capture the incidence and reasons for surgical cancellation. The tool was edited with permission to include patient characteristics such as age, sex, and specialty of surgery to be performed (AORN, 2016). The tool's validity was established through literature review and confirmation by a committee of experts in the perioperative domain. The OR schedules and booking are based on pre-established timetables of surgical specialties according to the $\mathrm{RMH}$ theatre practice. All cancelled cases were documented in the book of cancelled cases. The cancellation rate was calculated as the percentage of the total number of cancelled cases over the planned patients for surgery.

\section{Data analysis}

Data were entered in SPSS version 16 and analyzed using descriptive statistics like frequencies, percentages and presented in tables. 


\section{Ethical considerations}

Ethical clearance was obtained from the University of Rwanda, College of Medicine and Health Sciences Institution Review Board and study approval from RMH. No names were used on the checklist except the study assigned codes only for anonymity. The completed checklists were kept in a key-locked cabinet while soft data was locked with a password in the computer for confidentially. The collected data was for the study purpose only, without intent to implicate the hospital. The study findings were disseminated to the RMH intended for further use as a reference to improve related services as research-based evidence.

\section{Results}

About 736 patients were booked for surgical operation. The most booked procedures are general surgeries $(31.8 \%, n=234)$, orthopedic surgeries $(23.1 \%, 170)$, gynecology obstetric surgeries $(15.9 \%, \quad n=117)$ and maxillofacial surgeries $(11.1 \%, \mathrm{n}=82)$, and $179 \quad(24.3 \%)$ patients were cancelled on the day of surgery. The highest cancellation rate was $28.2 \%$ observed among orthopedic and general surgeries cases, followed by $27.4 \%$ among gynecology \&obstetric surgeries cases (Table 1).

Table 1. The booked and cancelled cases during the period of $1^{\text {st }}$ January to $31^{\text {st }}$ March 2017

\begin{tabular}{lcc} 
Procedures & $\begin{array}{c}\text { Booked cases } \\
\text { (\%) }\end{array}$ & $\begin{array}{c}\text { Cancelled } \\
\text { (\% of booked) }\end{array}$ \\
General surgeries & $234(31.8)$ & $66(28.2)$ \\
Orthopedic surgeries & $170(23.1)$ & $48(28.2)$ \\
Gynecology \&Obstetric & $117(15.9)$ & $32(27.4)$ \\
surgeries & $82(11.1)$ & $13(15.9)$ \\
Maxillofacial surgery & $71(9.6)$ & $11(15.5)$ \\
Urology & $32(4.3)$ & $5(15.6)$ \\
ENT surgery & $30(4.1)$ & $4(13.3)$ \\
Plastic surgery & $736(100.0$ & $179(24.3)$ \\
\hline
\end{tabular}

Total

736100.0

$179(24.3)$

Most cancelled patients were females and classified in the 31-40 age group (Table 2).

Table 2. The Age and Sex of cancelled participants

\begin{tabular}{llcc} 
Variable & & Frequency & Percent \\
\hline Age & $1-10$ & 13 & 7.3 \\
& $11-20$ & 11 & 6.1 \\
& $21-30$ & 21 & 11.7 \\
& $31-40$ & 48 & 26.8 \\
& $41-50$ & 26 & 14.5 \\
& $51-60$ & 26 & 14.5 \\
& $61-70$ & 17 & 9.5 \\
\multirow{2}{*}{ Sex } & $71-80$ & 14 & 7.8 \\
& $81-90$ & 3 & 1.7 \\
& Females & 92 & 51.4 \\
Total & Males & 87 & 48.6 \\
\hline
\end{tabular}


The main causes of cancelation (Table 3, Figure1) are surgeon related $(33.5 \%, \mathrm{n}=60)$, dominant in general $(46.7 \%, \mathrm{n}=28)$, orthopedic $(28.3 \%, \mathrm{n}=17)$ and obstetric surgeries $(13.3 \%, \mathrm{n}=8)$. They are followed by workup related caused cancellations $(24.6 \%, \mathrm{n}=44)$, also dominant in general surgeries $(25 \%, \mathrm{n}=11)$, in orthopedic surgeries $(31.8 \%, \mathrm{n}=14)$, and Gynecology \& obstetric surgeries ( $22.7 \%, \mathrm{n}=10)$. Patients related causes counted $17.3 \%(n=31)$, and surgical schedule run observed in $12.8 \%$ of operated patients $(n=23)$ were frequent in general surgery $(43.5 \%, \mathrm{n}=10)$ and Gynecology \& obstetric surgeries $(30.4 \%, n=7)$.

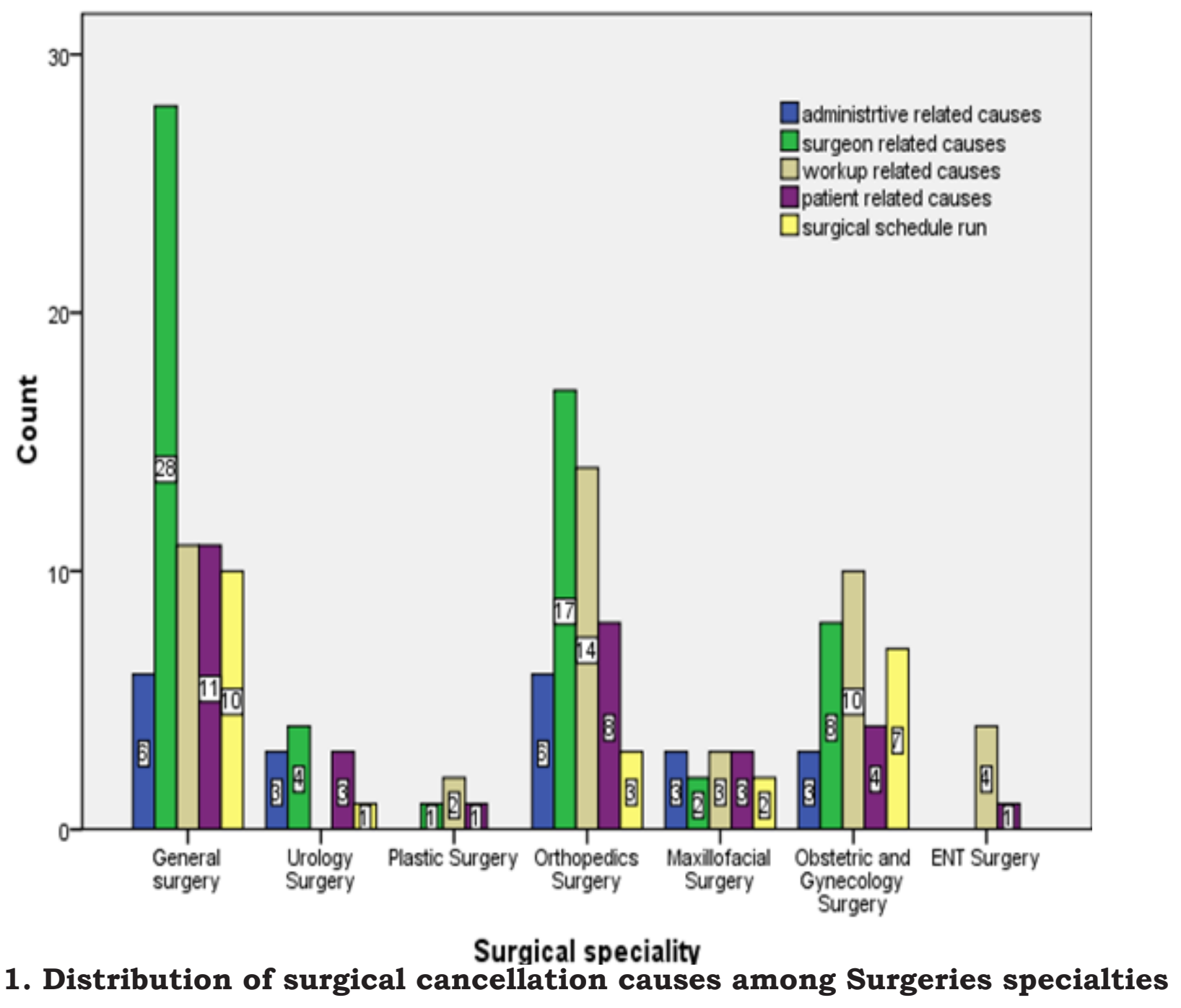


The time constrain/long list $(19.6 \%, \mathrm{n}=35)$, the surgeon not available, patient conditions acute change in medical status $(10.6 \%, \mathrm{n}=19)$, improved, prior case time overrun, and non-turn up of the patient $(8.4 \%, 15)$, abnormal emergence case priority respectively $(2.5 \%, n=5$ lab test results $(7.8 \%, n=14)$, Surgical equipment respectively) were the main reasons of surgical failure, unavailable equipment or technology, cancellation (Table 3).

equipment scheduling conflicts,

Table 3. Reasons for surgical cancellation in details

\begin{tabular}{|c|c|c|c|}
\hline \multicolumn{2}{|c|}{ Reason for surgical cancellation } & \multirow{2}{*}{$\begin{array}{c}\text { Frequency } \\
5\end{array}$} & \multirow{2}{*}{$\begin{array}{r}\text { Percent } \\
2.8\end{array}$} \\
\hline \multirow{7}{*}{$\begin{array}{l}\text { Administrative } \\
\text { related causes }\end{array}$} & Surgical equipment failure & & \\
\hline & $\begin{array}{l}\text { Unavailable equipment or } \\
\text { technology }\end{array}$ & 5 & 2.8 \\
\hline & Equipment scheduling conflicts & 5 & 2.8 \\
\hline & Unavailable implants & 2 & 1.1 \\
\hline & Instrument not available & 2 & 1.1 \\
\hline & Shortage of sterile instruments & 1 & 0.6 \\
\hline & $\begin{array}{l}\text { Acute disruption of water/ } \\
\text { electricity }\end{array}$ & 1 & 0.6 \\
\hline \multirow{8}{*}{$\begin{array}{l}\text { Surgeon related } \\
\text { causes }\end{array}$} & SUB-TOTAL & 21 & 11.7 \\
\hline & Time constraint/long list & 35 & 19.6 \\
\hline & Change on the surgical plan & 7 & 3.9 \\
\hline & Surgeon not available & 6 & 3.4 \\
\hline & No senior surgeon is available & 4 & 2.2 \\
\hline & Wrong decision/diagnosis & 4 & 2.2 \\
\hline & Waiting for consult & 3 & 1.7 \\
\hline & $\begin{array}{l}\text { Involved in different } \\
\text { emergencies }\end{array}$ & 1 & 0.6 \\
\hline \multirow{8}{*}{$\begin{array}{l}\text { Workup related } \\
\text { causes }\end{array}$} & SUB-TOTAL & 60 & 33.5 \\
\hline & Acute change in medical status & 19 & 10.6 \\
\hline & Abnormal lab test results & 14 & 7.8 \\
\hline & Incomplete pre-op preparation & 4 & 2.2 \\
\hline & Incomplete medical workup & 4 & 2.2 \\
\hline & $\begin{array}{l}\text { History and physical assess- } \\
\text { ment incomplete }\end{array}$ & 2 & 1.1 \\
\hline & Lab results not available & 1 & 0.6 \\
\hline & SUB-TOTAL & 44 & 24.6 \\
\hline \multirow{5}{*}{$\begin{array}{l}\text { Patient-related } \\
\text { causes }\end{array}$} & The patient is not turn up & 15 & 8.4 \\
\hline & The patient requested to cancel & 9 & 5 \\
\hline & Patient conditions improved & 5 & 2.8 \\
\hline & Pre-op instruction not followed & 2 & 1.1 \\
\hline & SUB-TOTAL & 31 & 17.3 \\
\hline \multirow{5}{*}{$\begin{array}{l}\text { Surgical schedule } \\
\text { run }\end{array}$} & Delayed starting time & 8 & 4.5 \\
\hline & Emergence cases override & 5 & 2.8 \\
\hline & Emergence case priority & 5 & 2.8 \\
\hline & Prior case time overrun & 5 & 2.8 \\
\hline & SUB-TOTAL & 23 & 12.8 \\
\hline GRAND TOTAL & & 179 & 100 \\
\hline
\end{tabular}




\section{Discussion}

Surgical cancellation and reasons for cancellation have been widely studied. The rate and reasons for surgical cancellations vary from one country, hospital or health setting to another. The cancellation rate was found to be $24 \%$ similar to a study conducted in South Arabia [11] and slightly lower than $27.2 \%$ revealed in a study done in India[13] and Hong Kong.[19]This rate was also higher than $7.6 \%,[7,15] 8.8 \%,[16] 4.4 \%$, [17] $8.5 \%,[18] 7.47 \%,[10]$ and $21.0 \%$ [1] found in the previous studies. This higher cancellation is frequently found in low-income countries where access to surgical services is a big concern. In addition, these countries have higher proportions of emergency cases such as cesarean deliveries and traffic road injuries that need emergency interventions [1, 7] compared to high-income countries. [5-7] This difference explains the higher cancellation rate found in our study in general, orthopedic, obstetrics and gynecology surgeries. Similar results were found in previous studies.[1, $7,13,19]$ Our finding showed that urology, ENT and maxillofacial are the least cancelled. Studies have shown that low-income countries have at least two operating theatres per 100000 people in addition to surgical burden from road accidents, injuries, different diseases that need surgical treatment, contrarily to at least 14 operating theatres per 100000 people for developed countries.[20, 21] Moreover, the more surgeries planned, the more the number of cancelled cases. [19] This is also the case in our study setting, which is classified under low-income countries where absences of operating theatre and shortage of essential surgical equipment and materials, surgical providers are common and delay surgical procedures.[20] Again, Table 1 shows that the number of cancellations increased with the number of surgeries performed.

Regarding reasons for surgical cancellation, again, the causes of surgical cancellation differ from hospital to hospital, region to region. Surgeon related causes varied as $41 \%$, [22] 34\% [11] $8.4 \%,[1] 7.2 \%$, [7] 2.7\%, [17] and low as $1 \%,[14]$ versus $33.5 \%$ in the present study. The theatre time constraint was reported as the main cause of surgical cancellation in previous studies and contributed 63\%, [19] 35.7\%,[10] 17.3\%, [23] and $10.2 \%,[1]$ to surgical cases cancellation. The overbooking, the overrun of previous surgery and the increased number of emergency surgeries contributed greatly to these cancellations. $[1,7]$ Scheduling of procedures that take a long time at the beginning of the day was found significant in the reduction of cancellation rate.[24]
The organizational structure of surgeons' duties and skills specifications that combine consultation, teaching and carrying out surgical procedures in addition to their shortage in low-income context would have contributed to delayed previous surgeries and increased runover reported in the study, and this was not within the scope of our data analysis.

Paramedical Work up related causes was found to be the second cause of cancellation in the present study $(24.6 \%)$ and a major cause of surgical cancellation in previous studies. $[16,17]$ The current study established that acute change in the patients' medical status contributed $10.6 \%$ of surgical case cancellations in tandem with other studies.[10, 17,19,23] Good preoperative assessment and preparation of the patient undergoing surgeries underpin surgical cancellation rate reduction related to an acute change in medical status.[5] However, not all cancellations related to change in medical status are patient preparation-related. This concept was not analyzed within the scope of the current study.

Non-turn up of the patient also contributed $6.6 \%$ [22] and $19.8 \%$ [25] surgical cancellation rate. The communication between the health care providers and the patient was found to be effective in reducing the absence of the patients on the day of surgery. [26] The surgical cancellation was also associated with surgical schedule run $(12.8 \%, \mathrm{n}=23)$ in the present study. This category of surgical cancellation causes was less studied, but its components such as emergence cases override, emergence case priority and prior case time overrun were analyzed in previous studies. Few cases in the present study were related to administrative/ facility-related causes in contrast to the others rates found in previous studies such as $82 \%,[1]$ $73 \%,[14] 34 \%,[11] 20 \%,[7,17]$ 17.5\%,[22] versus $11.7 \%$ in current study.

\section{Limitation}

The study was conducted in one hospital so that the findings could not be generalized to other Rwandan hospitals. In addition, the reasons for surgical cancellations recorded in a registry were not written as well as on the data collection checklist, and the data collector tried to relate the recorded reasons with ones on the data capturing checklist. Standardized documentation would help to capture surgical cancellation rate as an indicator of OR utilization effectiveness. 


\section{Conclusion}

The surgical cancellation rate at the study hospital is $24 \%$. The study revealed an upward trend of surgical cancellation increasing with the number of patients booked and the type of surgical procedure. A deep prospective study is required to gain more insight on the reason for surgical cancellations, which are amenable to mitigation measures.

\section{Acknowledgement}

We express our special thanks to the University of Rwanda that reviewed and approved this research.

We also acknowledge the surgical team and administrative body of Rwanda military hospital for a positive cooperation in this study.

\section{Authors' contribution}

UT: Study conception, proposal writing, data collection, data analysis and review and approval for submission.

JM: Study conception, proposal writing, data analysis, manuscript writing and review and approval for submission.

RD: manuscript writing, review and approval for submission.

OL: manuscript writing, review and approval for submission

\section{Declaration of conflict of interest}

We declare no conflict of interest

This article is published open access under the Creative Commons Attribution-NonCommercial NoDerivatives (CC BYNC-ND4.0). People can copy and redistribute the article only for noncommercial purposes and as long as they give appropriate credit to the authors. They cannot distribute any modified material obtained by remixing, transforming or building upon this article. See https:// creativecommons.org/licenses/by-nc-nd/4.0/

\section{References}

1. Chalya PL, Gilyoma JM, Mabula JB, Simbila $\mathrm{S}$, Ngayomela IH, Chandika AB, Mahalu W. Incidence, causes and pattern of cancellation of elective surgical operations in a university teaching hospital in the Lake Zone, Tanzania. Afr Health Sci. 2011; 11:438-443

2. Jawaid M, Moosa FA, Jaleel F, Khalique A. Cancellation on the intended day of surgery. Prof Med $J$.www.theprofesional.com . 2014;21:1-4

3. Pandit JJ, Carey A . Estimating the duration of common elective operations: Implications for operating list management. Anaesthesia.2006; 61:768-776
4. Rakesh G, Bhalotra AR, Bhadoria P, Gupta $\mathrm{N}$, Anand $\mathrm{R}$ Reasons for Cancellation of Cases on the Day of Surgery-A Prospective Study. Indian J Anaesthesia. 2009; 1:35-39

5. Souzdalnitski D, Narouze S. Evidence-based approaches toward reducing cancellations on the day of surgery. Saudi $J$ Anaesth. 2014.https://doi.org/10.4103/1658354X.143921

6. Dexter F, Tinat M, Carole S, Laura A, Epstein $\mathrm{RH}$. Relative Influence on Total Cancelled Operating Room Time from Patients Who Are Inpatients or Outpatients Preoperatively. Anesth Analg . 2014;118:p 1072-1080

7. Dhafar KO, Ulmalki MA, Felemban MA, Mahfouz ME, Baljoon MJ, Gazzaz ZJ, Baig M, Hamish NM, Althobaiti SA, Al-Hothali FT Cancellation of operations in Saudi Arabian hospitals: Frequency, reasons and suggestions for improvements. Pakistan $J$ Med Sci. 2015; 31:1027-1032

8. Chamisa I . Why is surgery cancelled? A retrospective evaluation. South African $J$ Surg. 2008; 46:79-81

9. Nicholson A, Coldwell CH, Lewis SR, Smith AF . Nurse-led versus doctor-led preoperative assessment for elective surgical patients requiring regional or general anaesthesia. Cochrane Database Syst Rev. 2013;11:1-35

10. Afzal F, Asad N, Ali K. Causes of Postponement of Elective Surgery. Biomedica. 2010; 26:148-151

11. Sultan N, Rashid A, Abbas SM . Reasons for cancellation of elective cardiac surgery at Prince Sultan Cardiac Centre, Saudi Arabia. $J$ Saudi Hear Assoc . 2012;24:29-34

12. Chang J-H, Chen K-W, Chen K-B, Poon K-S, Liu S-K .Case review analysis of operating room decisions to cancel surgery. BMC Surg .2014; $14: 47$

13. Nanjappa BAN, Kabeer KK, Smile SR . Elective Surgical Case Cancellation - an Audit Elective Surgical Case Cancellation Int J Cur Res Rev . 2015; 6:19-23

14. Chiu $\mathrm{CH}$, Lee A, Chui PT . Cancellation of elective operations on the day of intended surgery in a Hong Kong hospital: Point prevalence and reasons. Hong Kong Med $J$. 2012;18:5-10

15. El-Dawlatly A, Turkistani A, Aldohayan A, Zubaidi A, Ahmed A. Reasons Of Cancellation Of Elective Surgery In A Teaching Hospital. Internet J Anesthesiol. 2007; 15:1-5 
16. Kim KO, Lee J . Reasons for cancellation of elective surgery in a 500-bed teaching hospital: A prospective study. Korean $J$ Anesthesiol. 2014; 67:66-67

17. Kaddoum R, Fadlallah R, Hitti E, El-jardali F, Eid G El. Causes of cancellations on the day of surgery at a Tertiary Teaching Hospital. BMC Health Serv Res.2016; 1-8

18. Hovlid E, Bukve O, Haug K, Aslaksen AB, von Plessen $\mathrm{C}$. A new pathway for elective surgery to reduce cancellation rates. BMC Health Serv Res .2012;12:154

19. Kumar R, Gandhi R .Reasons for cancellation of operation on the day of intended surgery in a multidisciplinary 500 bedded hospital. $J$ ournal Anaesthesiolgy Clin Pharmacol .2012; 28:66-69

20. Harvard Chan School of Public Health .More than two billion people worldwide lack access to surgical services. Press Releases . 2010

21. World Health Organization . Bulletin of the World Health Organization. 2016
22. Ezike H, Ajuzieogu V, Amucheazi A . Reasons for elective surgery cancellation in a referral hospital. Ann Med Health Sci Res. 2011; 1:197-202

23. Dimitriadis PA, Iyer S, Evgeniou E. The challenge of cancellations on the day of surgery. Int J Surg . 2013;11:1126-1130

24.H.Epstein R, Dexter F . Rescheduling of Previously Cancelled Surgical Cases Does Not Increase Variability in Operating Room Workload When Cases Are Scheduled Based on Maximizing Efficiency of Use of Operating Room Time. Anesth Analg. 2013; 117:p 9951002

25. González-Arévalo A， Gómez-Arnau JI, DelaCruz FJ, Marzal JM, Ramírez S, Corral EM, García-del-Valle S . Causes for cancellation of elective surgical procedures in a Spanish general hospital. Anaesthesia .2009;64:487-493

26.Azari-Rad S, Yontef AL, Aleman DM, Urbach DR . Reducing elective general surgery cancellations at a Canadian hospital. Can $J$ Surg. 2013; 56:113-118 